\title{
Exploring technology opportunities and evolution of loT-related logistics services with text mining
}

\author{
Mu-Chen $\mathrm{Chen}^{1,2} \cdot$ Pui Hung Ho ${ }^{1}$
}

Received: 19 February 2021 / Accepted: 17 June 2021 / Published online: 27 June 2021

(c) The Author(s) 2021

\begin{abstract}
Many IoT technologies have been applied in the logistics industry in recent years, and they have had a substantial impact on many sectors such as shipping, air freight, warehousing, inventory, etc. Exploring technology opportunities and carrying out technological trend analysis are essential for IoT's evolution, and there are many techniques or methods for doing so. In this paper, data analysis and text mining techniques, technology opportunity analysis (TOA) and technology-service evolution analysis (TSEA) have been applied to analyze and observe IoT technologies' and services' evolution. Academic journals, market reports, and patents have been collected and reviewed on the topic of IoT in the logistics field in this paper. Moreover, by using TOA, technology opportunities have been analyzed to explore IoT-related logistics services. The results of TOA, for example, show that cloud technology is essential to develop smart logistics services, and communication RFID technologies are key to developing information logistics services. Finally, TSEA enables the observation of IoT technology and logistics service evolution by combining unstructured and semi-structured data from text documents. Observing the results of TSEA, the evolution of IoT in logistics is identified, and the results of TSEA also confirm those of TOA using unstructured or semi-structured text data from documents only. The results of this paper are discussed and compared with those of some previous review studies. In summary, the results of this paper provide methodological guidelines on this topic for a comprehensive understanding of IoT-related logistics services.
\end{abstract}

Keywords Internet of things $\cdot$ Logistics services $\cdot$ Text mining $\cdot$ Technology opportunity analysis $\cdot$ Technology-service evolution analysis

\section{Introduction}

Since technological advancements of the internet of things (IoT) surge in recent years, the importance of technology management is as influential to scholars as to practitioners in the industry. A myriad of technological innovations first start off with a technology push strategy but slowly transform to a possible market-pull concept when technological concepts gradually open up to the public. IoT is a convincing example and our focus in this paper; it has rapidly evolved as

Mu-Chen Chen

ittchen@mail.nctu.edu.tw

1 Department of Transportation and Logistics Management, National Chiao Tung University, 4F, No. 118, Section 1, Chung Hsiao W. Road, Taipei 100, Taiwan

2 Department of Transportation and Logistics Management, National Yang Ming Chiao Tung University, No. 1001, University Road, Hsinchu 30010, Taiwan an umbrella term envisioning that every object on Earth can be identified, controlled, and monitored through the Internet [4]. With IoT-related technologies like radio frequency identification (RFID) and wireless sensor networks (WSN) commonly known to practitioners, the analysis of IoT is vital, and should help provide guidance to both academics and market practitioners.

Many IoT technologies have been applied in the logistics industry for the past few years, and they have had a substantial impact. Gartner [19] forecast an economic value of IoT, in the global market, of USD 1.9 trillion in 2020, while McKinsey [18] estimated the potential economic impact of six major IoT applications to be USD 2.7 trillion to USD 6.2 trillion per year by 2025 . A collaborative report by DHL and Cisco in 2015 predicted that USD 8 trillion will be generated through new connections over the next ten years, where USD 1.9 trillion is from supply chains and the logistics industry [17], proving there is huge potential for countries to further increase their connectedness and prosper through 
trade, integration, and technology. In addition, another leading technology company, C3 Solutions, has presented white papers on IoT in transportation and logistics in recent years [3]. Also, an IoT World Congress was held in 2015 and again in 2016 in Barcelona, Spain, where industry speakers and experts were invited to join and hold exhibits, demonstrating the importance of this research topic.

IoT technologies have been used in various functions in the logistics process for improving operational performance. Due to the desire for real-time visibility and traceability of the food supply chain on the part of both enterprises and customers, the use of IoT for safety and quality control in logistics is arising in the agriculture industry [28]. IoT is able to increase visibility and control of the supply chain so that the security and traceability of goods are sustained in the logistics process [21]. Nižetić et al. [21] indicated that IoT is reforming logistics, and logistics can profit from IoT in areas such as inventory management, warehousing, routing, product quality management, vehicle tracking, communication between vehicles and supply chain members, and certification. Delivery in e-commerce mostly depends on logistics; however, logistics consumes a lot of resources [30]. Improving logistics performance is essential to e-commerce companies and logistics service providers; therefore, Wang et al. [30] developed an IoT-based intelligent system to improve the dispatching activities of logistics service. IoT can enable the connectedness of objects as well as data collection and information sharing; therefore, the integration of IoT with big data technologies can support data-driven management. According to the findings of a case study by Hopkins and Hawking [10], safety and sustainability in logistics are the planned emphases of IoT-driven big data analytics programs.

IoT is increasingly used and studied worldwide, and it is applied in the industry and at home [26]. From the research results of Shenkoya [26], it is clear that IoT positively influences the society and companies of countries studied in that research. Some examples of IoT applications in logistics are briefly presented as follows. The collaborative report by DHL and Cisco investigated three categories of applications, in warehousing, freight transportation, and last-mile delivery. For the details, readers can refer to report [17]. For retailing, both smart transportation and demand-aware warehouses are essential applications of IoT in logistics. Lee et al. [14] developed a warehouse management system (WMS) applying IoT for a manufacturing enterprise to facilitate smart logistics.

In recent years, because of the rising applications of IoT, there have been some reviews of the IoT literature in the areas of supply chain management (SCM) and logistics. Talavera et al. [28] adopted a systematic literature review approach to survey the IoT applications in the areas of agroindustry and environment with documents of papers, patents or technical reports. Talavera et al. [28] additionally presented some studies related to IoT applications in logistics, which are not covered in the scope of their review. Aryal et al. [1] conducted a systematic review based on latent semantic analysis to perform a survey of the research papers related to big data analytics and IoT in SCM. In addition, Rejeb et al. [23] performed a bibliometric analysis on journal papers related to IoT research work focusing on the areas of SCM and logistics. Ding et al. [8] surveyed the journal papers studying IoT in freight transportation, warehousing, and delivery to investigate how IoT influences smart logistics, and to indicate the challenges and future research directions of IoT-based smart logistics. Golpîra et al. [9] thoroughly surveyed the conference and journal papers related to IoT in logistics to suggest a common framework for IoT in logistics and directions for future research. Koot et al. [12] surveyed academic documents related to research on IoT advancements in the areas of SCM and logistics, focusing on integrating real-time data with decision making. Rejeb et al. [24] selected research papers to conduct a systematic literature review on IoT in a specific field of SCM, halal food supply chain and suggested future research works. Most of the previous review studies mentioned above involved surveying research papers, which were mainly collected from journals and conferences. The documents surveyed in the review study by Talavera et al. [28] included papers, patents or technical reports; however, the review scope did not cover IoT applications in logistics.

Due to the huge amount of text data from various sources, text mining techniques have been applied in several fields such as mining online reviews to discover the behavioral intentions of park visitors [16], mining online reviews for customer satisfaction analysis [5], online review classification [7], user-generated content analysis [31], service blueprint development [25] and supply chain risk management [6]. Moro et al. [20] used text mining software, Tools for Innovation Monitoring, to recognize the evolving technologies of renewable energy.

Exploring technological opportunities and analyzing technological trends are essential for IoT, with its rapidly changing nature, and there are many techniques or methods for doing so. Text mining has been used in technology opportunity analysis (TOA) to identify technological opportunities in the literature (e.g., [13, 27]). Previous studies [33, 34] have also applied TOA together with morphology analysis (MA) with the use of text mining to investigate technological opportunities. Yoon and Park [33] discussed the limitations of existing technology forecasting (TF) approaches. To encounter the limitations mentioned in Yoon and Park [33], they developed a keyword-based morphology analysis (MA) method, in which text mining is used to identify keywords and they are categorized with factor analysis to construct a keyword dictionary. Yoon et al. [34] also applied a keywordbased MA method to identify technological opportunities 
according to the relationship of technology morphology and product morphology. In Yoon et al. [34], the keywords of both technology and product are obtained by text mining. These methods are also suitable for studying IoT. Be that as it may, these methods may not be sufficient for analyzing IoT in the logistics services industry, due to the fact that data from the Internet is boundless yet unquantified, and lots of knowledge is hidden between the lines of text which cannot be utilized directly. The IEEE Internet of Things website (http://iot.ieee.org) is one example; information on conferences, education, publications, and more are all in texts available online. These semi-structured and unstructured data are extremely huge due to the popularity of IoT, where every object is linked by the Internet. In view of this, data analysis and text mining techniques are suitable for analyzing and observing the evolution of both IoT technologies and logistics services. A roadmap constructed by Tsai et al. [29] shows that with motivations and problems from IoT and its data, the solutions and results come from modeling of mining, mining algorithms for IoT and summarization; they also assess the dilemmas and future trends of potential changes. Therefore, this paper also applies technology-service evolution analysis (TSEA) to analyze the evolutions of IoT technology and service by combining unstructured and semi-structured data from text documents. The text mining technique can be applied to discover constructive information from massive unstructured text data [33], and technology opportunities can be identified from the huge data by using the intelligent method [34].

The present study has two research motivations. First, integrating IoT in logistics services is an intriguing topic to examine on its own. As logistics is fundamentally a networked business, adjustments to this network should be thoroughly analyzed to observe an overall picture ahead of consolidation between industries. As presented above, there have been some previous studies (e.g., [1, 23, 28]) that focused on providing reviews of IoT in SCM and/or logistics; however, they are relatively few. Therefore, the importance of developing IoT-based logistics services is essential and worth investigating. The second aspect of research motivations is to discover the evolution of IoT technologies and create value for logistics services. With the use of semistructured and unstructured data regarding IoT in logistics, ways to create value like developing logistics service models with IoT technology can be investigated more thoroughly. Thus, discovering the evolution of IoT can allow us to explore opportunities to add value to the logistics industry.

This paper attempts to apply text mining, TOA, and technology-service evolution analysis (TSEA) to analyze the opportunities and trends of IoT in the logistics services industry from both the perspectives of academia and practice to give an overall picture. The objectives of this paper are to: (1) use text mining to review academic literature, market reports and patents on IoT in the logistics field to give a comprehensive overview; (2) carry out TOA with MA for IoT in logistics services to observe new technology opportunities for IoT-based logistics services; and (3) with the above results, analyze the technology-service evolution of IoT-related logistics services with TSEA. The remainder of this paper is organized as follows. The next section presents the text mining-based analysis method including TOA and TSEA. The next section presents the data collected and analyzed in this paper, and the results of analysis. The results are also discussed in the folowing section. Finally, the last section draws a conclusion for this study.

\section{Text mining-based analysis method}

\section{Framework of method}

The IoT paradigm foresees the development of the current environment towards new enriched spaces [2]. To address the surge of technological advancements in IoT, an abundance of solutions has emerged to interconnect smart objects for systems with different scales and objectives in recent years. To keep a competitive edge in technology levels in the logistics service industry, there is presently a need to analyze the current situation and investigate future enhancements of IoT-based logistics services. Therefore, by applying text mining, TOA, and TSEA, this paper aims to bring insights into the problem, explore future trends, and uncover the evolution of IoT technology and logistics service to provide references to both academics and practitioners. The research methodology framework of this paper is schematically illustrated in Fig. 1. Solid lines represent research processes, and dotted lines represent research methods to be adopted. The process of the analysis method is as follows. First, it defines the research area of interest. Second, it collects data for analysis. Third, a three-stage analysis procedure is used to pre-process the collected data, and then to perform further analyses. Finally, the obtained results are discussed, and guidelines are drawn for IoT-based logistics services.

\section{The detailed procedure}

\section{Define area of interest}

There are many kinds of services in the logistics industry, including air, sea, rail, and road freight transportation; warehousing and distribution; customs, security and insurance, and many more. As there are countless logistics services available, this paper narrows the extent of logistics services of interest to two categories: freight transportation, and warehousing and distribution, considering the complexity of operations in warehousing, sea, land, and air transport and

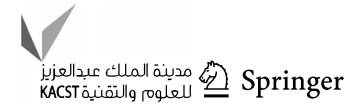


Fig. 1 The research methodology framework

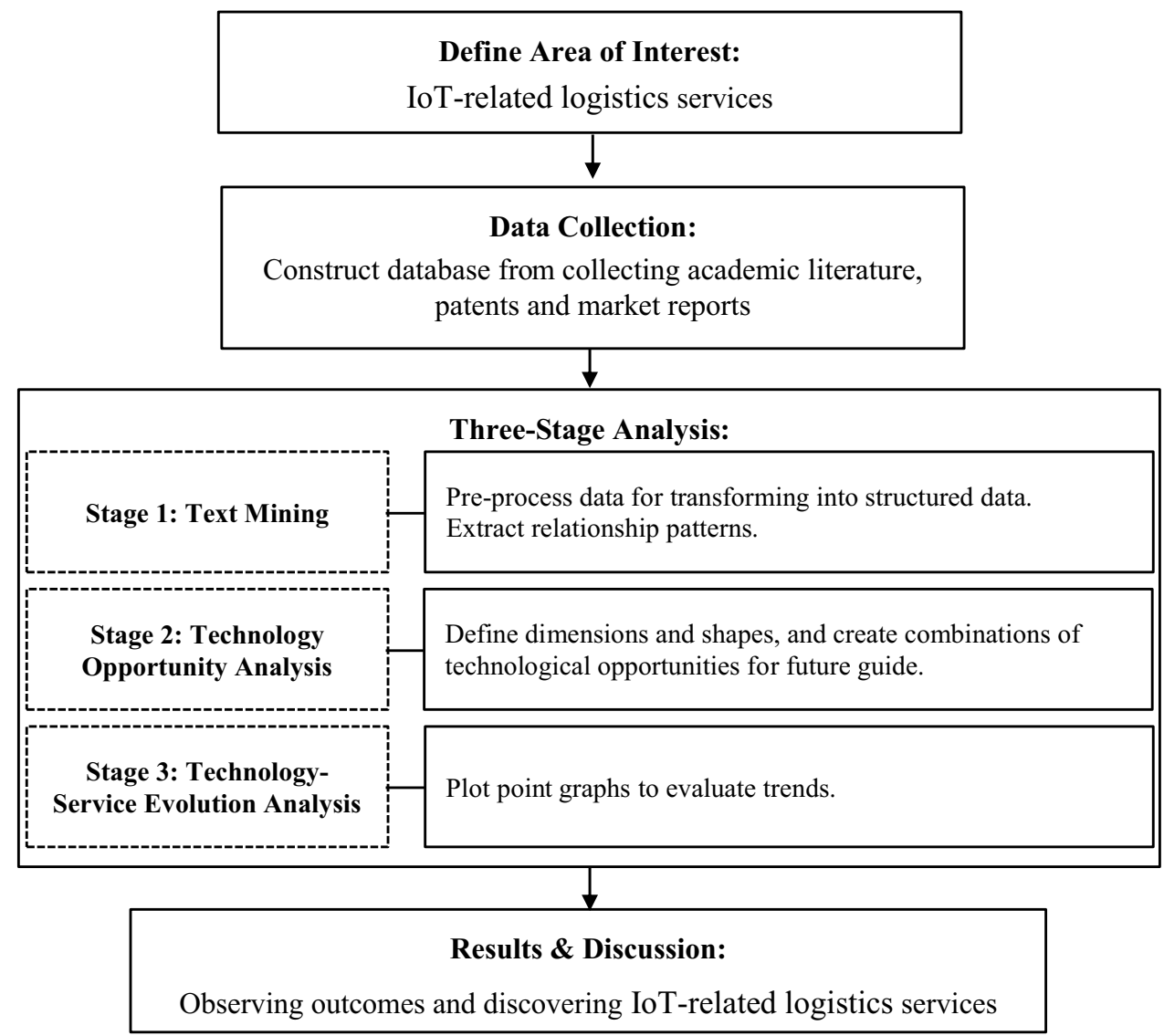

their interconnections. This paper applies text mining, TOA and TSEA to study the development of IoT-related logistics services and observe their changes. The scope of the study is based on related academic literature, patents, and news or market reports available, with the aim of achieving new insights using these data for analysis.

\section{Data collection}

Academic literature, patents, market reports, newspaper reports, and magazines relevant to IoT-related logistics services are collected as raw data to compile the initial database. Academic literature is collected from electronic databases including Science Direct, IEEE Xplore, Taylor \& Francis Online, Wiley Online Library Journals and eBooks and Emerald Insight. Patents are collected from the World
Intellectual Property Organization (WIPO)'s Patentscope, which is a global patent database. Academic literature and patents are collected if they satisfy the search strategy and inclusion criteria, similar to that of Cavalcante et al. [4], as shown in Table 1. Market-related information is collected from the IoT Solutions World Congress website, which contains presentations at the World Congress in 2016, and all the latest news including industry, sponsors and partners, events, press releases, and interviews from 2015 to 2016.

\section{Three-stage analysis}

The whole analysis process consists of three stages, including text mining, TOA, and TSEA. For the three-stage analyses procedure, in Stage 1, text mining is used to pre-process the collected data and extract relationship patterns. In Stage

Table 1 Search strategy and inclusion criteria for data collection

\begin{tabular}{ll}
\hline Search strategy & Search inclusion criteria \\
\hline Title/Abstract: (Iinternet of things OR IoT OR web of things or WoT)) & $\begin{array}{l}\text { (1) The document presents and/or discusses scenarios, research } \\
\text { challenges, and opportunities on the integration of IoT and rel- } \\
\text { AND ((logistics OR logistic OR freight transportation OR sea freight OR logistics services } \\
\text { air freight OR rail freight OR road freight OR warehouse OR warehous- } \\
\text { ing OR distribution)) }\end{array}$ \\
$\begin{array}{l}\text { (2) The document presents a strategy on how to integrate IoT and } \\
\text { logistics services }\end{array}$ \\
\hline
\end{tabular}


2, TOA is applied to analyze the technological opportunities. In Stage 3, TSEA is adopted to analyze the trends of IoT-related logistics services.

\section{Stage 1: Text mining}

Text mining extracts useful information from collected text documents. First, the collected text data are pre-processed to transform them into structured data for the following analysis. Documents are separated into the two logistics services topics-freight transportation, and warehousing and distribution-for analysis. During the extraction process, text data are analyzed to identify single words and word phrases relevant to IoT-related logistics services. Then, the extracted data are further divided into service-related data and technology-related data. In the stage of text mining, the process consists of two parts: data pre-processing and construction of a terms set, and extraction of relationship patterns for IoT-related logistics services. The process of Stage 1 is schematically illustrated in Fig. 2. The steps of data pre-processing and construction of the set of terms for IoT-related logistics services are described as follows:

\section{Step 1: convert source data to a standard format}

For ease of further analysis, all data imported are converted to a standard format. This is because the data from all academic literature, patents and market reports may be in formats such as databases, formats that represent data in rows and columns, or in document formats (e.g. Microsoft Word, Adobe PDF, or HTML).

Step 2: identify candidate terms

Candidate terms are words or groups of words that are used to identify concepts in text [11]. Every time extraction is performed, linguistic resources are used. Linguistic resources exist in the form of templates, libraries, and compiled resources, and may also be added manually. To identify candidate terms, a number must be set to limit the extraction of terms with a minimum global frequency, meaning that the minimum number of times which a word or a phrase must occur in the text for it to be extracted must be specified. This limit may greatly affect extraction results. For example, a limit above 1 generates results of sea freight (1), air freight (2), road freight (2), and freight transportation (2). However, if the limit of global frequency is increased to 5 or above, freight (7) will be the only result.

Step 3: identify equivalence classes and integration of synonyms to form concepts

After candidate single words (uniterms) and candidate compound words (multiterms) are identified, equivalence classes are identified. Synonyms regarding technologies and services are integrated using the most frequent form in the full-text content. Equivalence class is the base form of a phrase or a single form of two variants of the same phrase [11].

\section{Step 4: Assign a type}

Following Step 3, types are assigned to the extracted concepts. A type is a semantic grouping of concepts; types consist of higher-level concepts, positive and negative words, first names, places, organizations, and more. The types "technology-related" and "service-related" are the main focus of this paper.

Step 5: Index

The corpus of academic literature, patents and market information is indexed by establishing a pointer between
Fig. 2 Flowchart of stage 1: text mining

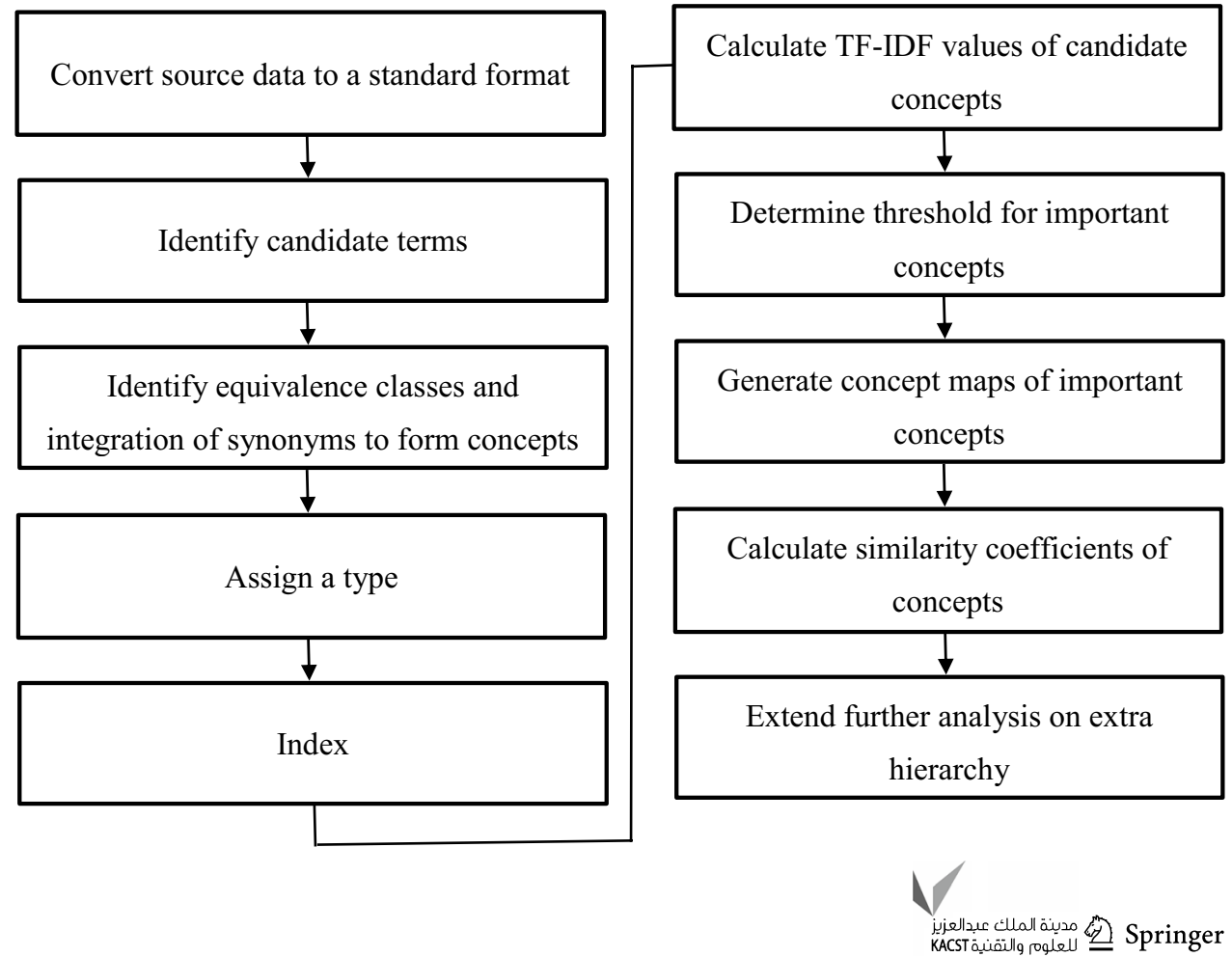


a text position and the representative term in each of the equivalence classes. In this step, the global frequency is calculated for root forms of words, where the global frequency is the total number of times that a concept appears in the entire set of documents.

By applying text mining, text can be classified and grouped into several layers: terms, concepts and types, from the bottom level to the upper level. During the extraction process, all of the text data are scanned, and the relevant concepts are identified, extracted and assigned to types. After constructing the structured data set of IoT-related logistics services, relationship patterns can be extracted, and the extraction procedure is described as follows:

Step 1: calculate TF-IDF values of candidate concepts

After the collected text data are pre-processed, candidate terms and concepts are identified. Subsequently, statistical analysis and clustering can be done. Statistical analysis can be adopted in the process of selecting terms and concepts. In this paper, term frequency-inverse document frequency (TF-IDF) [15] is applied to concepts. TF-IDF is a weight often used in information retrieval and text mining; it is a statistical measure used to evaluate how important a word is to a document in a collection or corpus, and it can describe important keywords which are closely associated with IoTrelated logistics services while avoiding general terms.

Step 2: determine threshold for important concepts

After TF-IDF values are calculated, a threshold is set to determine important concepts to be kept for further analysis. The determination of a threshold is a subjective, trial-anderror task. A reasonable value has to be selected so that the structure of the connectivity network becomes clearly visible [32]. In this paper, the threshold is set at the same level for both technology-related concepts and service-related concepts.

Step 3: generate concept maps of important concepts

Following the identification of important concepts of technologies and services, a concept map is plotted for each of the important technology concepts using the similarity metric to display their relationships. This allows the exploration of the set of concepts that are related to the selected concept. Filtering out which concepts to display is also possible by editing the settings such as which types to include, what kinds of relationships to look for, and so on. The maximum number of concepts on the map is not fixed; however, the concept map must display the corresponding important service concepts at the same time.

Step 4: calculate similarity coefficients of concepts

Henceforth, with important terms and concepts labelled and concept maps built, co-occurrence between selected concepts can be obtained. Co-occurrence reflects the underlying relationship between two concepts. In this paper, the similarity coefficient (SC) [11] is used to calculate the similarity value for co-occurrence, as expressed in Eq. (1):

$$
\mathrm{SC}_{i j}=\frac{\left(C_{i j}\right)^{2}}{\left(C_{i} \times C_{j}\right)},
$$

where $\mathrm{SC}_{i j}$ : similarity coefficient of concepts $i$ and $j ; C_{i}$ : number of documents or records in which concept $i$ occurs; $C_{j}$ : number of documents or records in which concept $j$ occurs; $C_{i j}$ : number of documents or records in which concept pair $i$ and $j$ co-occurs.

The similarity coefficient ranges from 0 to 1 , where a value of 1 means that the two concepts always appear together and never separately. The similarity coefficient result is then multiplied by 100 , and rounded to the nearest whole number. Similarity coefficients between all important technology-related and service-related concepts are required for the next stage of analysis.

\section{Step 5: Extend further analysis on extra hierarchy}

Currently, the focus of this stage of text mining is on the hierarchy of concepts; however, this process can also be extended to a lower layer of terms. Repeating Steps 3 and 4 of this stage, analysis of the important technology-related concepts and the terms under a particular service-related concept can be done.

\section{Stage 2: Technology opportunity analysis (TOA)}

After distinguishing terms, concepts, and types from texts in the corpus using text mining, these results can act as inputs for TOA supported by MA. The basic idea of MA is that the subject is broken down into several dimensions. A system can be decomposed into several subsystems, and MA systematically categorizes the possible combinations of subsystems [34]. The strength of this approach is the ability to model complex problems in a non-quantitative manner, and text mining is one method for supporting this analysis. The TOA procedure is schematically illustrated in Fig. 3, and it is described as follows:

\section{Step 1: form morphological matrix}

The morphological matrix under MA is based on the framework design of Yoon et al. [34], with a three-level categorization of dimensions, shapes and keywords. They are matched to types, concepts and terms generated from text

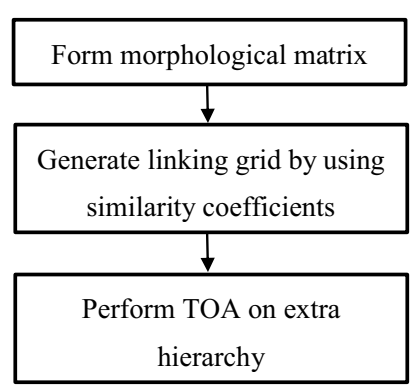

Fig. 3 Flowchart of stage 2: TOA 
mining. Thus, matching the levels between text mining and MA, results of text mining can be utilized in MA.

Step 2: generate linking grid by using similarity coefficients

Assimilating outcomes of text mining into MA, outcomes in the morphological matrix become an indicator for TOA. TOA is the process of gathering intelligence and providing foresight analysis for developing technologies [22]. The tasks that TOA performs in this paper include identifying:

- Component technologies and how they relate to each other in IoT-related logistics services;

- How technological emphases are shifting over time in IoT-related logistics services;

- Institutional strengths and weaknesses as identified in documents.

With text mining, data regarding IoT-related logistics services and their technologies are separated for analysis. With the use of similarity values between concepts of logistics services and technologies, a linking grid based on the morphological matrix can be generated. For example, as shown in Table 2, there are two dimensions each with two shapes under existing technologies; whereas there are three dimensions each with two shapes under existing logistics services. The similarity coefficients (SC) between shapes show the relationships between technologies and logistics services, where a higher SC implies higher potential technological opportunities in logistics services. Furthermore, the corresponding dimensions and shapes are recognized; thus, developing a combination of categorized IoT-related logistics services is possible.

Step 3: perform TOA on extra hierarchy

Utilizing results of Stage 1, a morphological matrix can be constructed and TOA can be carried out for the lower hierarchy of terms as well, comparing the relatability of technology-related concepts and terms under a particular service-related concept.

\section{Stage 3: Technology-service evolution analysis}

Outcomes from TOA can be incorporated with data of document publication years to carry out an evolution analysis for observing and validating whether results from previous stages are compatible. TSEA can be divided into three steps. This analysis is simple and effective, and also a suitable method for the collected data. The reason for carrying three different analytical steps is because similarity coefficients are based on individual concept frequencies together with co-occurring frequencies. Therefore, it is necessary to examine them to validate TOA results in Stage 2. The procedure of TSEA is schematically illustrated in Fig. 4, and the steps are described as follows:

Step 1: plot point graph of each important concept

All collected documents have a publication year. For each important technology-related and service-related concept, sort the publication years from oldest to newest, and plot a point graph against the years. Using the density and curvature of points, trends can be observed, and we can evaluate whether they are emerging, disappearing, mature, constant or temporary, etc.

Step 2: convert frequency of publication years to percentage

To compare publication year paired trends between technology-related and service-related concepts, because of the difference in document frequencies, the publication year frequencies are converted to percentages. With the total publication frequency as $100 \%$, the overall trend, as well as

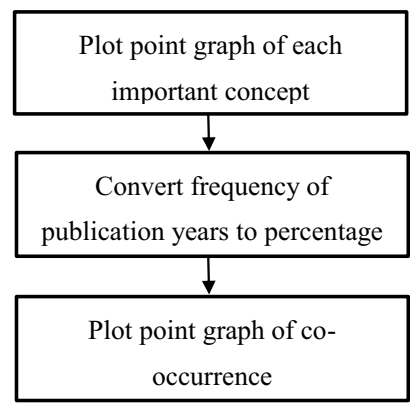

Fig. 4 Flowchart of stage 3: TSEA
Table 2 Template of linking grid between existing technologies and logistics services

\begin{tabular}{|c|c|c|c|c|c|c|}
\hline & \multirow[b]{3}{*}{ Dimension } & \multirow{3}{*}{$\begin{array}{l}\text { Dimension } \\
\text { Shape }\end{array}$} & \multicolumn{4}{|c|}{ Existing technologies } \\
\hline & & & \multicolumn{2}{|l|}{ I } & \multicolumn{2}{|l|}{ II } \\
\hline & & & 1 & 2 & 3 & 4 \\
\hline \multirow{6}{*}{$\begin{array}{l}\text { Existing logis- } \\
\text { tics services }\end{array}$} & \multirow[t]{2}{*}{ I } & 5 & $\mathrm{SC}(1,5)$ & $\mathrm{SC}(2,5)$ & $\mathrm{SC}(3,5)$ & $\mathrm{SC}(4,5)$ \\
\hline & & 6 & $\mathrm{SC}(1,6)$ & $\mathrm{SC}(2,6)$ & $\mathrm{SC}(3,6)$ & $\mathrm{SC}(4,6)$ \\
\hline & \multirow[t]{2}{*}{ II } & 7 & $\mathrm{SC}(1,7)$ & $\mathrm{SC}(2,7)$ & $\mathrm{SC}(3,7)$ & $\mathrm{SC}(4,7)$ \\
\hline & & 8 & $\mathrm{SC}(1,8)$ & $\mathrm{SC}(2,8)$ & $\mathrm{SC}(3,8)$ & $\mathrm{SC}(4,8)$ \\
\hline & \multirow[t]{2}{*}{ III } & 9 & $\mathrm{SC}(1,9)$ & $\mathrm{SC}(2,9)$ & $\mathrm{SC}(3,9)$ & $\mathrm{SC}(4,9)$ \\
\hline & & 10 & $\mathrm{SC}(1,10)$ & $\mathrm{SC}(2,10)$ & $\mathrm{SC}(3,10)$ & $\mathrm{SC}(4,10)$ \\
\hline
\end{tabular}


each publication year, can be compared between a paired technology-related and service-related concept.

Step 3: plot point graph of co-occurrence

After looking at technology-related and service-related concepts separately and paired, this step is to observe publication years of co-occurring concepts. Again, plot point graphs for sorted document publication years from oldest to newest. However, unlike Step 1, the point graph is for publication years with both relevant technology-related and service-related concepts appearing in the same document.

Drawing up results of all analyses using the three-stage analysis procedure, potential IoT-related technologies and logistics services are identified. Additionally, changes since the rise of IoT are identified by observing its evolution.

\section{Results and discussion}

\section{Review of data collection}

Academic journals, patents, and market news and reports regarding IoT and logistics under the specified search strategy and search criteria are the three categories of document data collected.

\section{Academic journal articles}

The five sources of journal articles are Science Direct, IEEE Xplore, Taylor \& Francis, Wiley and Emerald Insight. Only

Table 3 Summary of collected academic papers

\begin{tabular}{lll}
\hline Data source & $\begin{array}{l}\text { Number of academic } \\
\text { papers after applying } \\
\text { search strategy }\end{array}$ & $\begin{array}{l}\text { Number of academic } \\
\text { papers after manual } \\
\text { filtering }\end{array}$ \\
\hline Science Direct & 88 & 72 \\
IEEE Xplore & 67 & 40 \\
Taylor \& Francis & 41 & 16 \\
Wiley & 14 & 5 \\
Emerald Insight & 16 & 11 \\
Total & 226 & 144 \\
\hline
\end{tabular}

articles from journals have been included, no books or conference papers; the included articles may be published or available online for early access, and all articles are in English. The numbers of documents collected after applying the search strategy and after manual filtering are shown in Table 3. The documents have been checked to exclude any duplicates.

\section{Patents}

For patents collected from WIPO Patentscope, all patents in English from any country worldwide have been included in the data collection. The numbers of patents collected after applying the search strategy and after manual filtering are 502 and 223 , respectively.

\section{Market reports and news}

For market-related information collected from the IoT Solutions Word Congress website, the full documents of reports and news being included for analysis as market documents do not have separation of the abstract and content. All market documents are in English, and the detailed document types and numbers of documents are listed in Table 4.

\subsubsection{Summary of collected data}

The summary of collected documents is shown in Table 5, with 144 academic journal articles, 223 patents and 36 market reports and news; a total of 403 documents with 134,524 words. Although there are fewer market reports and news than the other two types, considering the fact that the whole document is being included for analysis, the text data are sufficient.

\section{loT-related logistics services data set}

After documents have been collected, IBM SPSS Modeler Text Analytics 18.0 is used for generating concepts from all of the documents. A total of 14,226 concepts have been generated initially; the output concepts are then examined and integrated by synonyms. After that, the technology-related

Table 4 Summary of collected market news, reports and presentations

\begin{tabular}{lll}
\hline Data source & Type of market documents & $\begin{array}{l}\text { Number of market } \\
\text { documents after manual } \\
\text { filtering }\end{array}$ \\
\hline IoT solutions world congress website media and resources hub & $\begin{array}{l}\text { News (global industry news, event } \\
\text { news, interviews) }\end{array}$ & 12 \\
& Reports (white papers) & 10 \\
& Congress presentations & 14 \\
\hline
\end{tabular}


Table 5 Number of documents collected and number of words included

\begin{tabular}{lll}
\hline Document type & $\begin{array}{l}\text { Total number of } \\
\text { documents }\end{array}$ & $\begin{array}{l}\text { Total } \\
\text { number of } \\
\text { words }\end{array}$ \\
\hline Academic articles & 144 & 28,897 \\
Patents & 223 & 41,518 \\
Market reports and news & 36 & 64,109 \\
Total & 403 & 134,524 \\
\hline
\end{tabular}

and service-related concepts have been assigned to two types, with all other types such as unknown, location, organization, etc. excluded from extraction. In total, there are 45 technology-related and 55 service-related concepts. After all concepts under the types 'technology-related' and 'service-related' have been clearly labelled, TF-IDF values are calculated as shown in Tables 6 and 7.

Setting the cutoff level of TF-IDF values as equal to or greater than 0.05 , from the results in Tables 6 and 7, the important technology-related concepts are: communication technology, RFID (radio frequency identification) technology, sensor technology, technology, cloud technology, mobile technology and GPS (global positioning system) technology; whereas the important service-related concepts are: information service, smart service, service, customer service and delivery service.

\section{Results of text mining}

\section{Technology-related concepts vs. service-related concepts}

With the use of IBM SPSS Modeler 18.0 Text Analytics, concept maps have been generated to discover the relationship between each technology and the five important services. Figure 5 has been modified manually from the outputs of SPSS Modeler 16.0 for clearer visualization. The core technology-related concept is bracketed in dotted lines, and the corresponding relevant service-related concepts are

Table 6 TF-IDF values of 45 technology-related concepts and determination of importance

\begin{tabular}{lllll}
\hline Concept & Global & Docs & TF-IDF & $\begin{array}{l}\text { Impor- } \\
\text { tant } \\
(\geq 0.05)\end{array}$ \\
\hline Communication technology & 249 & 123 & 0.105 & Yes \\
RFID technology & 355 & 108 & 0.161 & Yes \\
Sensor technology & 414 & 101 & 0.195 & Yes \\
Technology & 169 & 84 & 0.087 & Yes \\
Cloud technology & 230 & 71 & 0.128 & Yes \\
Mobile technology & 101 & 43 & 0.068 & Yes \\
GPS technology & 71 & 35 & 0.051 & Yes \\
\hline
\end{tabular}

Table 7 TF-IDF values of 55 service-related concepts and determination of importance

\begin{tabular}{lllll}
\hline Concept & Global & Docs & TF-IDF & $\begin{array}{l}\text { Impor- } \\
\text { tant } \\
(\geq 0.05)\end{array}$ \\
\hline Information service & 559 & 187 & 0.162 & Yes \\
Smart service & 286 & 62 & 0.171 & Yes \\
Service & 157 & 54 & 0.100 & Yes \\
Customer service & 227 & 45 & 0.156 & Yes \\
Delivery service & 119 & 40 & 0.086 & Yes \\
\hline
\end{tabular}

circled. The similarity coefficient of each link is noted as marked next to the circle in Fig. 5. For example, in Fig. 5, the concept map displays the relationship and similarity coefficients between the core technology-related concept communication technology and five important service concepts. The similarity is highest between information service and communication technology, with a similarity coefficient of $18 \%$; and the lowest among the five service-related concepts is between delivery service and communication technology, with a similarity coefficient of $4 \%$. Other similarity coefficients have been obtained from the remaining six concept maps with core technology-related concepts of RFID technology, sensor technology, technology, cloud technology, mobile technology and GPS technology for use in the next stage of analysis.

\section{Technology-related concepts vs. delivery service's underlying terms}

Apart from text mining between technology-related concepts and service-related concepts, an additional lower hierarchy of terms has been analyzed rather than using concepts for all. As an example, as the concept of delivery service is more connected and applicable to the logistics industry to a literal extent, it may be intriguing to investigate more in-depth into specific services under delivery and their textual relationship with different technologies. Hence, concept maps have been generated between technology-related concepts and terms under the concept of delivery service. As an example in Fig. 6, with cloud technology as the core technology-related concept, the delivery-service-related terms with similarity coefficients greater than zero include service delivery $(5 \%)$, flexible delivery $(2 \%)$, smart delivery $(1 \%)$ and delivery $(1 \%)$.

\section{Results of technology opportunity analysis}

\section{Technology-related concepts vs. service-related concepts}

Utilizing terms, concepts, and types from text mining, morphological matrices showing keywords, shapes, and 


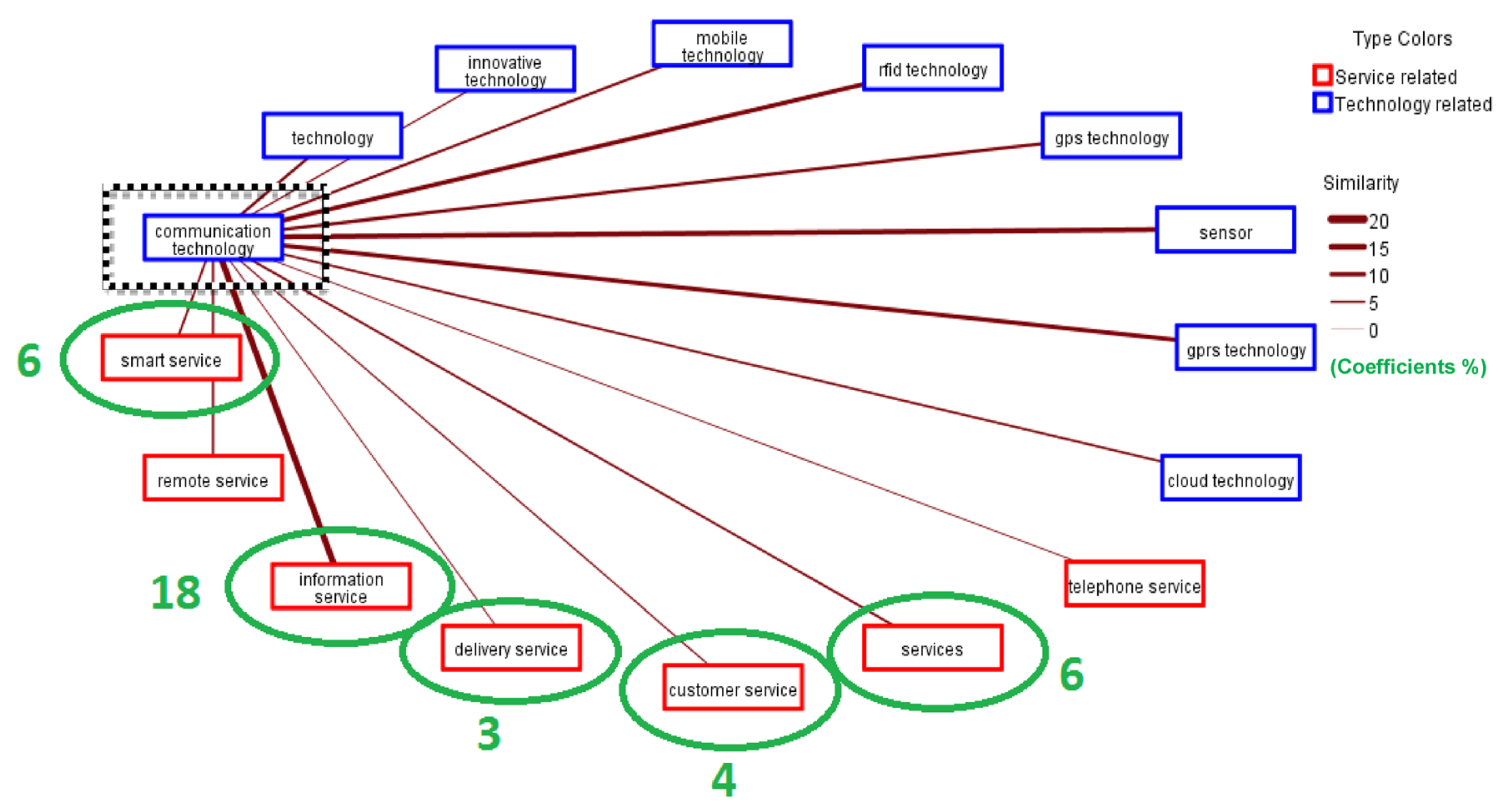

Fig. 5 Concept map of communication technology ( modified from outputs of SPSS Modeler 16.0)

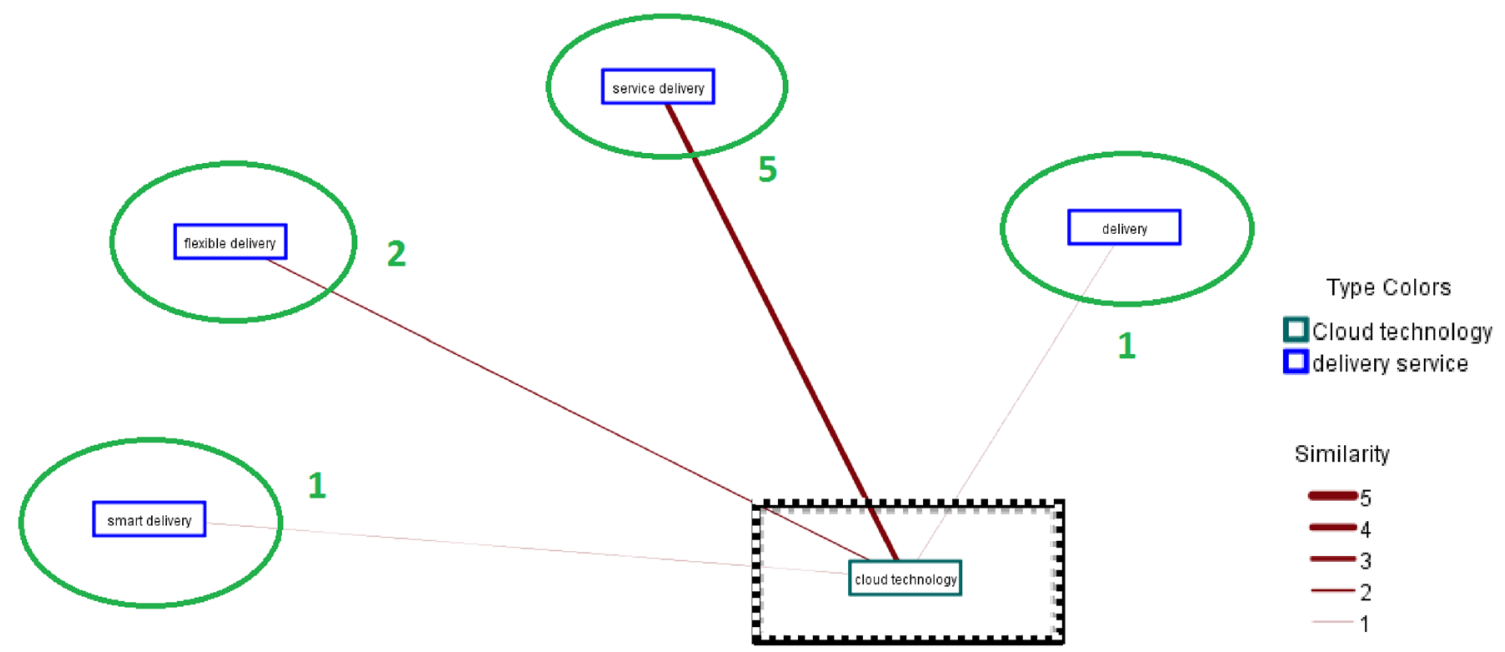

Fig. 6 Concept map of cloud technology with terms under-delivery service concept ( modified from outputs of SPSS Modeler 16.0)

dimensions have been constructed as in Table 8 for seven important technology-related and five important servicerelated concepts. Additionally, by inserting results of similarity coefficients from "IoT-related logistics services data set", a $7 \times 5$ linking grid has been constructed with a technology-related morphological matrix against a servicerelated morphological matrix (Table 9).

Observing the linking grid in Table 9 and the output of similarity coefficients, technology opportunities exist for the highest similarity coefficients for each technology and service, and thus insights from this part are summarized as follows:
1. From a technology point of view:

- Communication, RFID, sensor, GPS and general technologies are most relevant for developing information services;

- Cloud and mobile technologies are most relevant for developing smart services.

2. From a service point of view:

- Communication technologies are most commonly used for information services; 
Table 8 Morphological matrix of important concepts

\begin{tabular}{|c|c|c|c|c|c|c|}
\hline Dimension & Shape & \multicolumn{5}{|l|}{ Keyword } \\
\hline \multirow{7}{*}{ Technology-related } & Communication & \multicolumn{5}{|c|}{ Communication device, communication network, etc } \\
\hline & RFID & \multicolumn{5}{|c|}{ RFID technology, cargo radio frequency, radio frequency reader writer, etc } \\
\hline & Sensor & \multicolumn{5}{|c|}{ Biomedical sensor, digital edge node sensor, sensor electrode, etc } \\
\hline & Technology & \multicolumn{5}{|c|}{ Technologies, technology } \\
\hline & Cloud & \multicolumn{5}{|c|}{ Centralized micro-cloud, cloud database, cloud-enabled platform, etc } \\
\hline & Mobile & \multicolumn{5}{|c|}{ Ubiquitous mobile computing, mobile device, etc } \\
\hline & GPS & \multicolumn{5}{|c|}{ GPS device, telematics GPS, GPS-guided navigation, etc } \\
\hline \multirow[t]{5}{*}{ Service-related } & Information & \multicolumn{5}{|c|}{ Cargo information, earthquake information, actionable information, etc } \\
\hline & Smart & \multicolumn{5}{|c|}{ Smart terminal, smart parking, smart route, etc } \\
\hline & Service & \multicolumn{5}{|c|}{ Services, service } \\
\hline & Customer & \multicolumn{5}{|c|}{ Better customer service, customer experience, customer satisfaction, etc } \\
\hline & Delivery & \multicolumn{5}{|c|}{ Cargo delivery, city delivery, collaborative delivery, etc } \\
\hline \multirow[t]{8}{*}{$\begin{array}{l}\text { Table } 9 \text { Linking grid of } \\
\text { important technology-related } \\
\text { concepts against service-related } \\
\text { concepts }\end{array}$} & Similarity coefficients $(\%)$ & $\begin{array}{l}\text { Information } \\
\text { service }\end{array}$ & Smart service & $\begin{array}{l}\text { Service (not } \\
\text { specified) }\end{array}$ & $\begin{array}{l}\text { Customer } \\
\text { service }\end{array}$ & $\begin{array}{l}\text { Deliv- } \\
\text { ery } \\
\text { service }\end{array}$ \\
\hline & Communication technology & 18 & 6 & 6 & 4 & 3 \\
\hline & RFID technology & 17 & 3 & 1 & 1 & 1 \\
\hline & Sensor technology & 13 & 12 & 5 & 6 & 4 \\
\hline & Technology (not specified) & 16 & 10 & 6 & 5 & 3 \\
\hline & Cloud technology & 11 & 13 & 12 & 9 & 5 \\
\hline & Mobile technology & 8 & 16 & 6 & 3 & 4 \\
\hline & GPS technology & 7 & 2 & 4 & 4 & 2 \\
\hline
\end{tabular}

- Mobile technologies are most commonly used for smart services;

- Cloud technologies are most commonly used for customer, delivery and general services.

3. Overall:

- Cloud technology is highest in total similarity coefficients with all other services;

- Information service is highest in total similarity coefficients with all other technologies.

\section{Technology-related concepts vs. terms in delivery service concept}

Following "Technology-related concepts vs. service-related concepts", with an extra lower hierarchy for delivery services in text mining, a linking grid has been also generated for those with similarity coefficients greater than zero (Table 10). There are other delivery services appearing in the documents such as indirect delivery, outbound delivery, collaborative delivery, etc.; however, as their similarity coefficients are zero, they have not been included in Table 10 . Likewise, some insights are summarized as follows:
Table 10 Linking grid of additional hierarchy under delivery service concept

\begin{tabular}{lllll}
\hline $\begin{array}{l}\text { Similarity coefficients } \\
(\%)\end{array}$ & $\begin{array}{l}\text { Delivery } \\
\text { service }\end{array}$ & $\begin{array}{l}\text { Service } \\
\text { delivery }\end{array}$ & $\begin{array}{l}\text { Smart } \\
\text { delivery } \\
\text { service }\end{array}$ & $\begin{array}{l}\text { Flexible } \\
\text { delivery } \\
\text { service }\end{array}$ \\
\hline $\begin{array}{l}\text { Communication tech- } \\
\text { nology }\end{array}$ & 1 & 1 & 2 & 0 \\
RFID technology & 1 & 0 & 0 & 0 \\
Sensor technology & 2 & 1 & 2 & 0 \\
Technology & 4 & 4 & 1 & 0 \\
Cloud technology & 1 & 5 & 1 & 2 \\
Mobile technology & 1 & 1 & 6 & 0 \\
GPS technology & 1 & 0 & 0 & 0 \\
\hline
\end{tabular}

1. From a technology point of view:

- RFID, sensor, GPS and general technologies are most relevant for developing general delivery services;

- Cloud and general technologies are most relevant for developing service delivery;

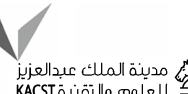


- Communication, sensor and mobile technologies are most relevant for developing smart delivery services.

2. Overall:

- Similarity coefficients are much lower than the linking grid between concepts due to insufficient data for the lowest hierarchy of terms;

- Cloud and general technologies are highest in total similarity coefficients with all other delivery services;

- Service delivery and smart delivery services are highest in total similarity coefficients with all other technologies.

Although the results in Table 10 are not significant enough to draw conclusions, no modifications have been done, as low similarities may provide insights, in the sense that these low similarity coefficients may represent new, innovative ideas or obsolete, unimportant ideas. If academic journals and patents were the only document types included, the number of citations could be an index for further analysis; however, as market reports are also included, the publication year has been used, and evolution analysis has been done in the next stage.

\section{Results of technology-service evolution analysis}

As a validation of the analytical results of Stages 1 and 2, the evolution analysis has been carried out to authenticate whether the outcome of text-only data resembles the outcome of data additionally including the document publication year. Additionally, TSEA is also applied to analyze the evolution of both IoT technology and service by combining unstructured and semi-structured data from text documents.

\section{Data preparation for TSEA}

This analysis employs data of document frequencies and publication years for studying the evolution of both IoT technologies and logistics services. Table 11 indicates the number of documents published and the number of important concepts published each year. The earliest document was published in 2008, and the newest is published in 2017 (up till 15th March 2017). Figure 7 consists of bar charts of the data in Table 11; the shapes of the bar charts are similar except for the year 2017, where the number of important concepts in documents is proportionally smaller than the number of documents published compared to other years. However, documents of the year 2017 are only collected up till 15th March 2017, so no conclusion can be drawn at this stage on why this is significantly lower.
Table 11 Number of documents and important concepts published each year

\begin{tabular}{lll}
\hline Year & $\begin{array}{l}\text { Number of documents } \\
\text { published }\end{array}$ & $\begin{array}{l}\text { Number of important } \\
\text { concepts in docu- } \\
\text { ments }\end{array}$ \\
\hline 2008 & 2 & 3 \\
2009 & 0 & 0 \\
2010 & 6 & 9 \\
2011 & 28 & 74 \\
2012 & 28 & 63 \\
2013 & 20 & 35 \\
2014 & 77 & 196 \\
2015 & 129 & 311 \\
2016 & 83 & 221 \\
2017 & 30 & 41 \\
\hline
\end{tabular}

Table 12 shows document frequencies of important individual technology-related and service-related concepts (the numbers in brackets under each concept) together with cooccurring concepts (the numbers in cells intersecting one technology-related and one service-related concept). For example, the individual document frequency for the communication technology concept is 123 times, and the cooccurring frequency between communication technology and information service is 65 times. As can be seen from Table 12, the results are consistent with those obtained from TOA.

\section{Sorted document publication year of each important concept}

Having sorted document publication years regarding seven technology-related and five service-related concepts from oldest to newest and plotted them as point graphs to observe the trends, growing trends are observed for all 12 important concepts (Figs. 8, 9). Longer horizontal lines represent more documents published in a particular year. Figure 8 indicates that the longest horizontal lines mostly lie in the years 2014, 2015, and 2016, showing a mature state and gradual slowdown in many of the technology-related concepts. For the service-related concepts, the mature state shown in Fig. 9 may not be as obvious as that of technology-related concepts, since documents of the year 2017 are only collected up till 15th March 2017.

\section{Percentage of paired concepts' document publication years}

For the second step of TSEA, individual concept frequency is converted into percentage according to the publication year to compare paired concepts, and bar charts have been drawn for all 12 important concepts. Taking results of similarity coefficients from Table 10, and looking from a 

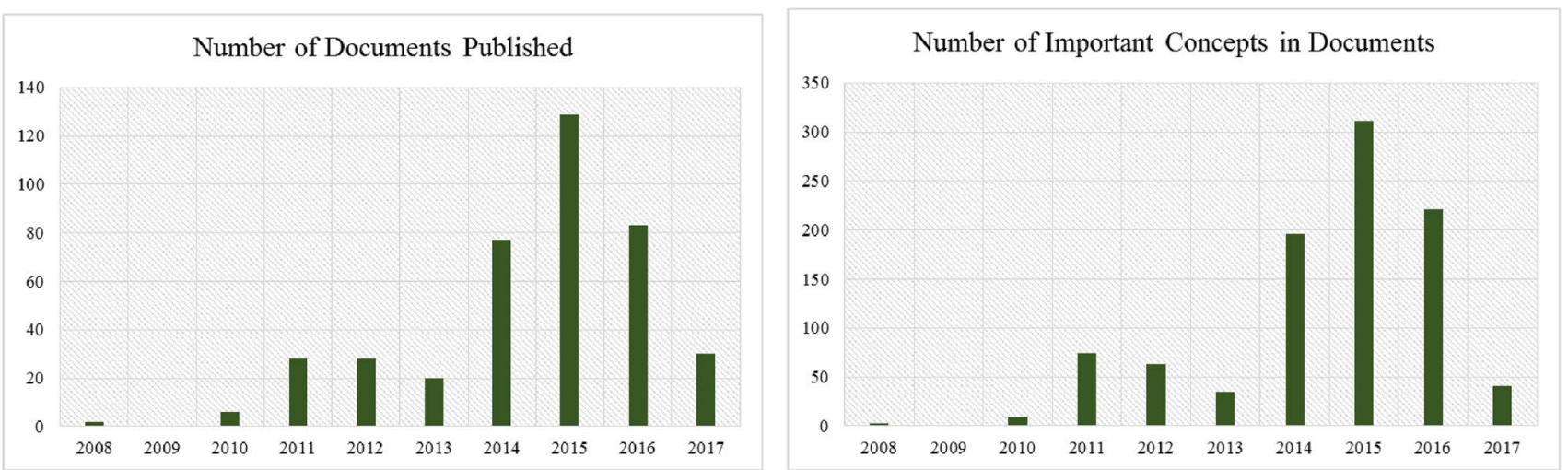

Fig. 7 Bar charts of numbers of documents and important concepts published each year

Table 12 Document frequencies of each important concept and co-occurring concepts

\begin{tabular}{llllll}
\hline Document frequency (out of 403) & $\begin{array}{l}\text { Information } \\
\text { service (187) }\end{array}$ & $\begin{array}{l}\text { Smart } \\
\text { service } \\
(62)\end{array}$ & Service (54) & $\begin{array}{l}\text { Customer } \\
\text { service (45) }\end{array}$ & $\begin{array}{l}\text { Delivery } \\
\text { service } \\
(40)\end{array}$ \\
\hline Communication technology (123) & 65 & 22 & 20 & 16 & 13 \\
RFID technology (108) & 60 & 16 & 8 & 8 & 9 \\
Sensor technology (101) & 51 & 28 & 18 & 17 & 14 \\
Technology (84) & 51 & 23 & 17 & 15 & 11 \\
Cloud technology (71) & 39 & 24 & 22 & 17 & 12 \\
Mobile technology (43) & 26 & 21 & 12 & 8 & 9 \\
GPS technology (35) & 22 & 8 & 9 & 8 & 6 \\
\hline
\end{tabular}

technology-related concepts point of view with the highest similarity coefficients, Figs. 10, 11, 12, 13, 14, 15 and 16 show the paired trends. All in all, the results of paired concept trends are consistent with results of similarity coefficients; with higher similarity coefficients, the paired trends are more alike (Figs. 10, 11, 12, 13). From Figs. 14, 15 and 16 , we see that the disparities between technology and service trends are quite distinct, with over $15 \%$ being the biggest difference between technology and service bars, e.g. for paired percentages between cloud technology and smart service (Fig. 14), the largest difference in 2016 is $23 \%$. This result may be because the numbers of documents for several concepts are comparatively small, which leads to greater differences.

\section{Sorted document publication years of co-occurring concepts}

Having sorted publication years and plotted point graphs for co-occurring concepts, with a 10-year document publication year range (2008-2017), the results indicate that the higher the similarity coefficients, the more dispersed the publication years. Again, taking results of similarity coefficients from Table 10, and looking from a technology-related concepts point of view with the highest similarity coefficients, Fig. 17 shows the co-occurring trends, where all points are distributed over five years or more. Some other co-occurring trends may appear only in three to four publication years. In particular, for the co-occurrence between RFID technology and information service, the points are scattered over a total of nine years, and at the same time, there is a high similarity coefficient of $17 \%$, meaning that RFID technology and information service's relationship can be seen from structured data (publication years) as well as unstructured data (texts from documents), validating the consistency of similarity coefficients results.

\section{Discussion}

From the results of text mining in"Technology-related concepts vs. delivery service's underlying terms", although the search strategy in "Define area of interest" includes warehousing as the main aspect in the area of interest, results show that warehousing is not significant, as no concept is directly related to warehousing after analysis. One possible reason is that IoT and warehousing's application together is simply common sense to people in the industry; therefore, little additional research has been done on this topic.

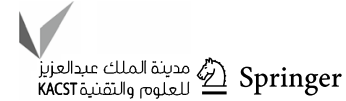



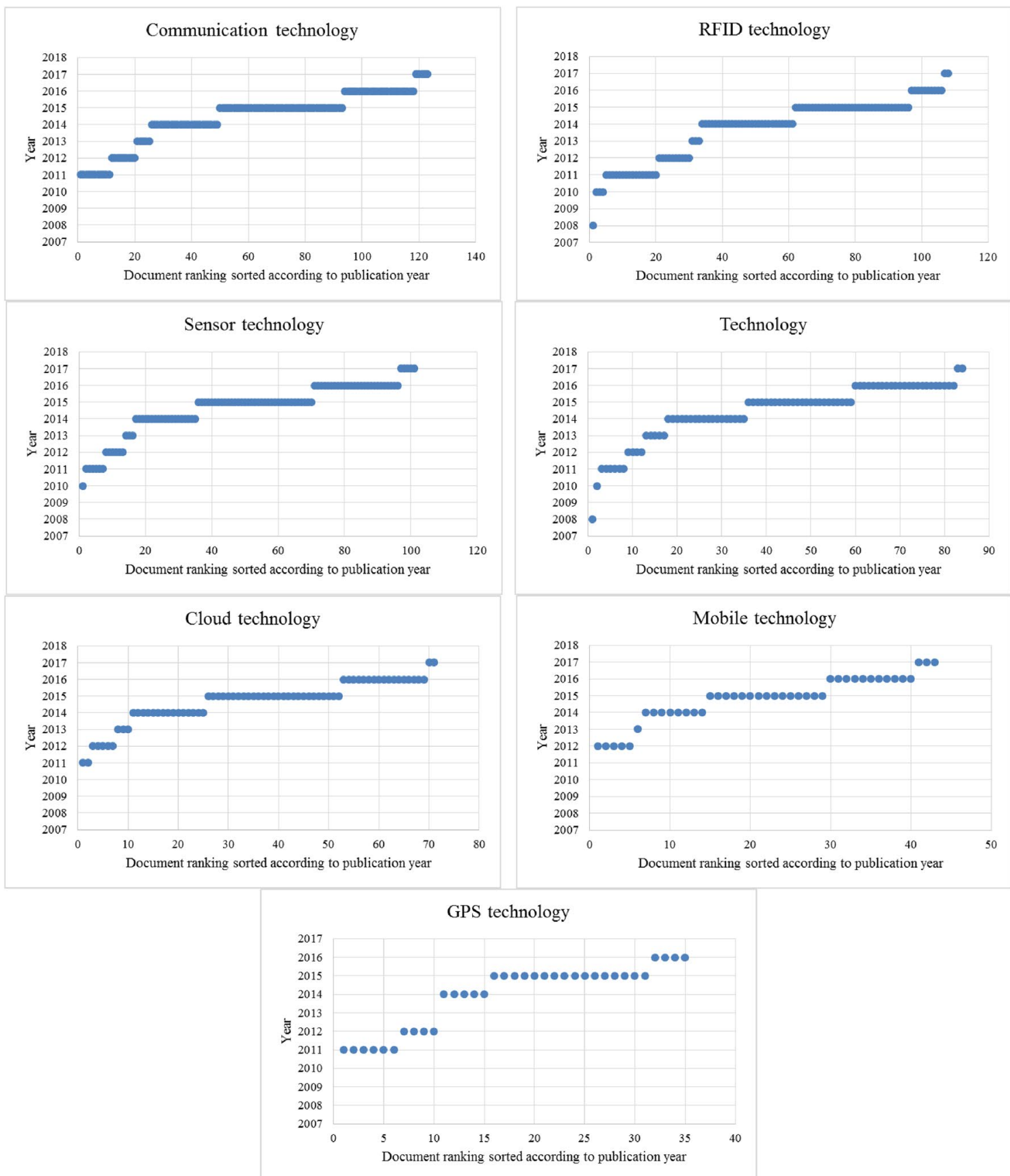

Fig. 8 Sorted publication years of documents with important technology-related concepts

Furthermore, by analyzing two hierarchies in TOA, results can guide different people in the industry. Operational level can refer to results of the lowest hierarchy of terms to examine detailed operational relationships, whereas managerial level can refer to the middle level of concepts to examine tactical or strategic relationships between technologies and services.

The results of TSEA in "Technology-related concepts vs. terms in delivery service concept" are consistent with the results of TOA in "Technology-related concepts vs. delivery service's underlying terms". The results of TSEA with the addition of structured data of document publication years confirm the results of TOA with unstructured or semi-structured text data from documents only. There have been no negative trends or unrelated concepts for terms and concepts with high similarity coefficients.

Golpîra et al. [9] stated that logistics is one of the main implementation areas of IoT. Additionally, in recent years, 

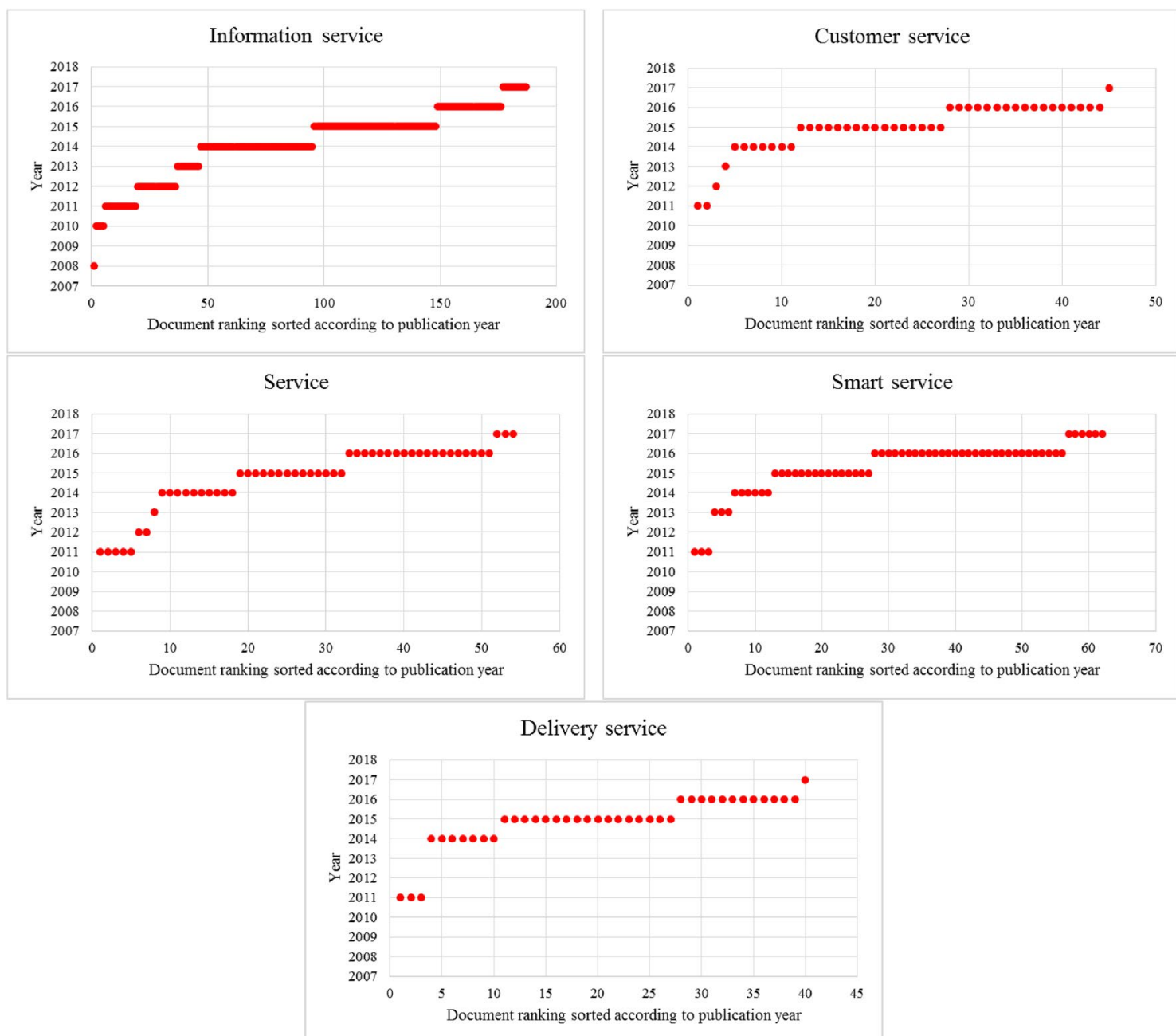

Fig. 9 Point graphs of sorted publication years of documents with service-related concepts

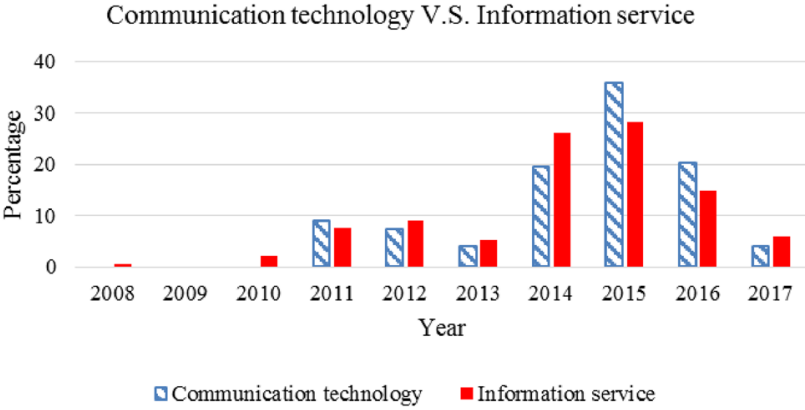

Fig. 10 Paired percentage year distributions-communication technology and information service

it was recognized by academia and practices that innovative SCM strategies need to be established for reacting to the new business environment caused by IoT [1]. Nowadays, information and communication technologies are fundamental to logistics services, particularly to smart logistics services.

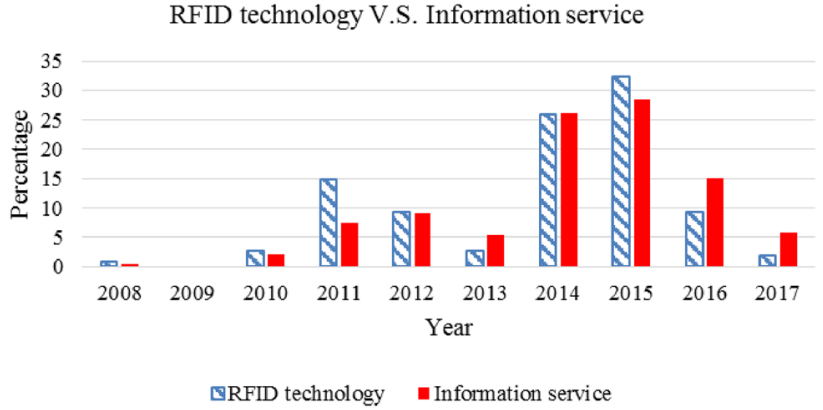

Fig. 11 Paired percentage year distributions-RFID technology and information service

Aryal et al. [1] stated that big data and IoT facilitate better decision-making for SCM through information visibility initiated by real-time data technologies such as collection, storage, processing and sharing. Due to the advancement of big data analytics (BDA) and artificial intelligence (AI), 


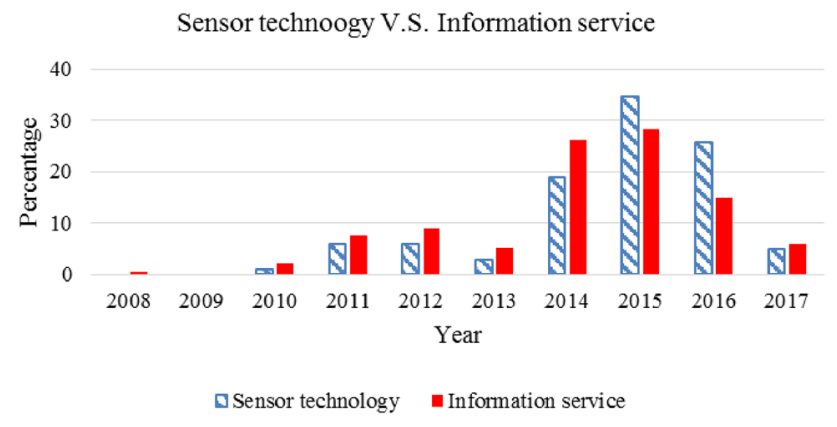

Fig. 12 Paired percentage year distributions—-sensor technology and information service

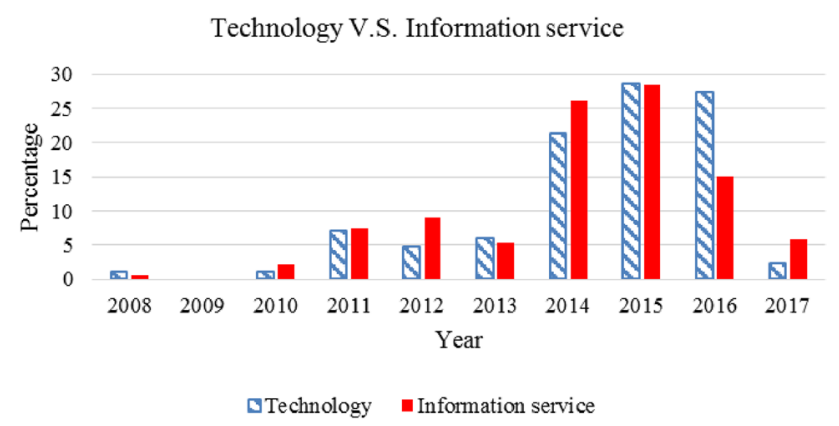

Fig. 13 Paired percentage year distributions - technology and information service

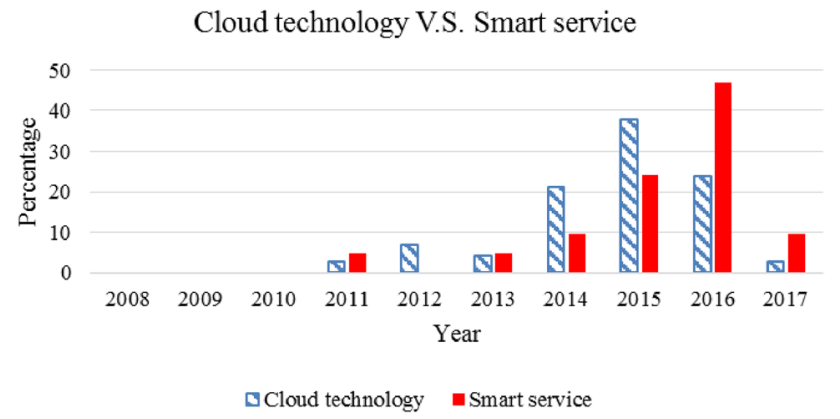

Fig. 14 Paired percentage year distributions-cloud technology and smart service

smart logistics has been valued by industries. As mentioned in "Introduction", in recent years, there have been some reviews of the IoT literature in the areas of SCM and logistics. The results of this paper are compared to those of some previous review studies herein. From the results of TOA presented in "Technology-related concepts vs. delivery service's underlying terms", information and communication technologies such as communication, RFID, sensor and GPS are essential to developing information services for logistics. From the work by Ding et al. [8], RFID, wireless sensor network and ZigBee are three terms of technologies, which

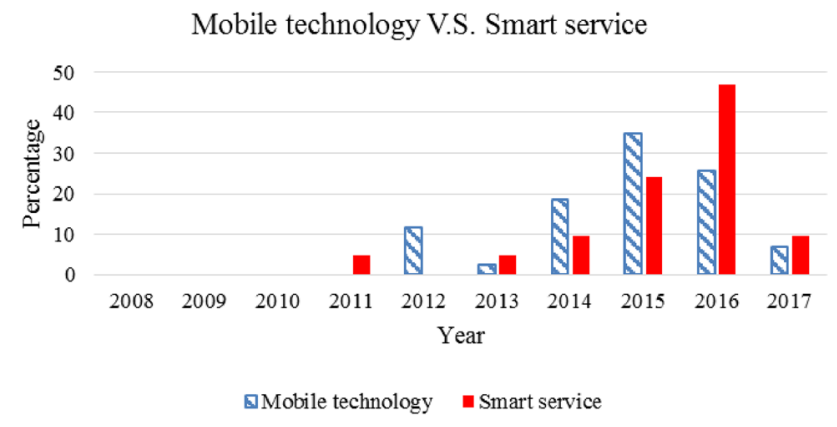

Fig. 15 Paired percentage year distributions-mobile technology and smart service

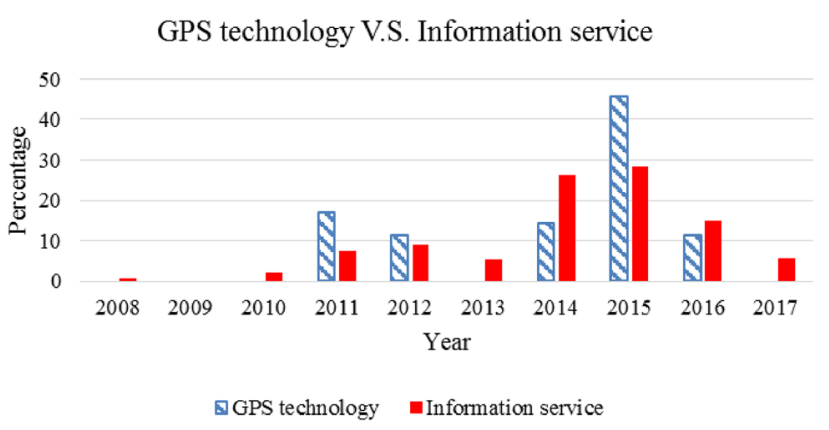

Fig. 16 Paired percentage year distributions-GPS technology and information service

are most frequently incorporated with IoT-based logistics. From the perspective of IoT technology, the results of this paper are almost consistent to that of Ding et al. [8]. The results of the survey in Rejeb et al. [23] also indicated that RFID is the technology most frequently mentioned in the journal papers analyzed by them in the area of IoT in SCM and logistics. Moreover, the bibliometric analysis done by Rejeb et al. [24] indicated that RFID is emphasized in the field of IoT in halal food supply chain as well.

Cloud and mobile technologies are essential to smart logistics. For the development of smart delivery services, communication, sensor and mobile technologies are most vital. Ding et al. [8] indicated that big data, cloud technology and AI can help in the advancement of smart logistics. Koot et al. [12] stated that integrating IoT with big data to enable supply chain and logistics analytics is possibly a very advantageous research issue. Additionally, Golpîra et al. [9] pointed out the necessity of changed data processing techniques for the real-time aggregation and analysis of big data created from IoT in the application area of logistics. Furthermore, the cloud technology enables the capability of logistics information system to respond to the conditions entailed by the data collected by IoT in a real-time and dynamic manner [8]. The results presented in "Technology-related concepts vs. terms in delivery service concept" show a mature 

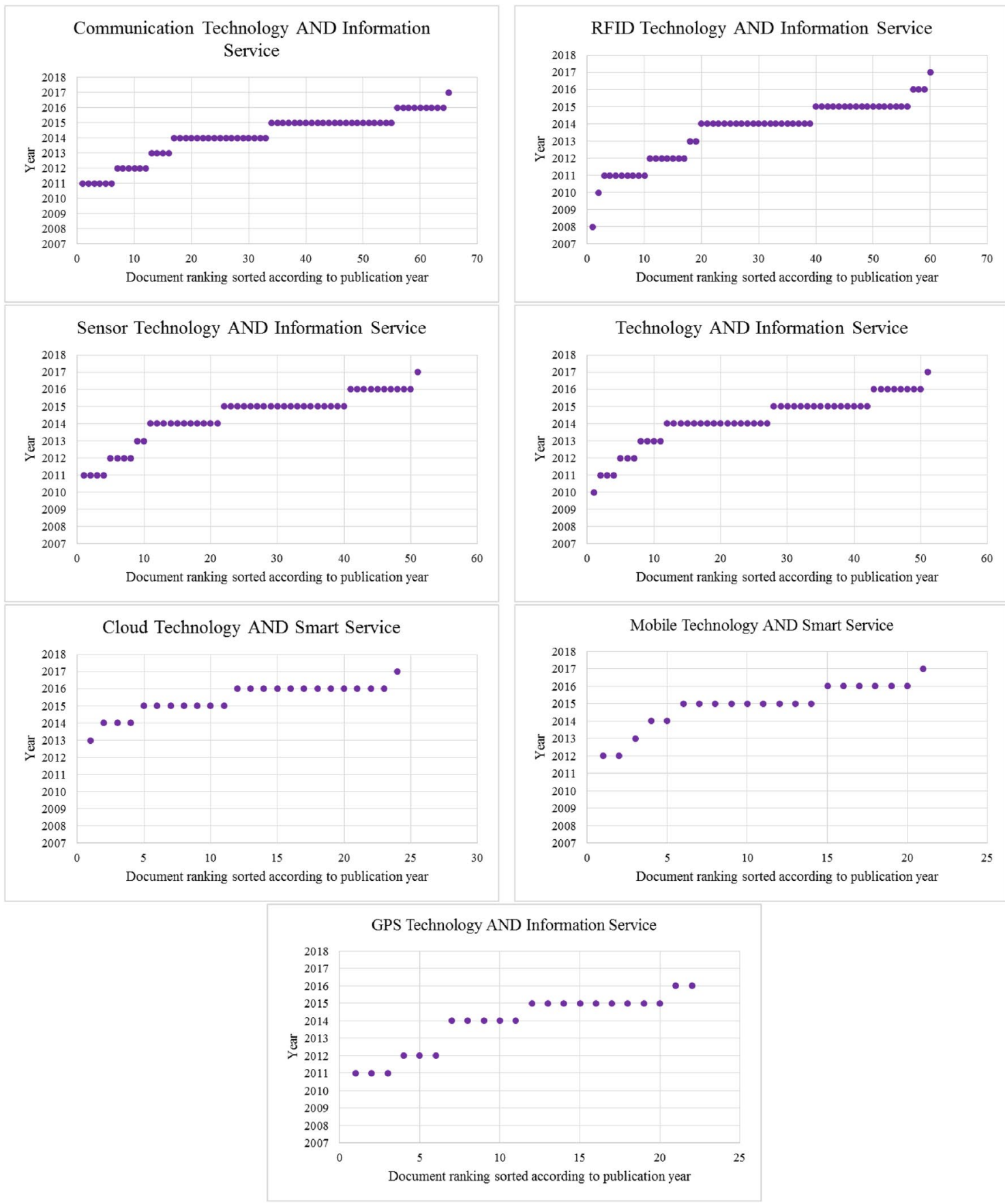

Fig. 17 Sorted publication years of co-occurring concepts

state and gradual slow-down in many of the technologyrelated concepts. However, for the service-related concepts, there may not exist a similar mature state. Based on this observation, the IoT applications in logistics services maybe still growing in 2017. From the results of the bibliometric analysis obtained by Rejeb et al. [23], the number of journal papers concentrating on IoT in SCM and logistics in the first decade of the 2000s had a significant growth; however, it fluctuated in the period from 2010 to 2020 .

\section{Conclusions}

The first contribution of this paper is that by using text mining, academic papers, patents and market reports on the topic of IoT in the logistics field have been analyzed. With the transformation of IoT as a technologypush concept to a combination of technology-push and market-pull integrated topic, collecting academic, patent, and market-based documents supports the provision of a 
comprehensive overview in this paper. The second contribution is that with the use of TOA, technology opportunities have been observed to explore IoT-related logistics services, for example, with the use of cloud technology to develop smart logistics services, or with RFID technology to develop logistics information services. The third contribution of this paper is applying TSEA to observe the evolution of IoT technology and logistics service by combining initial structured data, document publication years in this case, with unstructured and semi-structured data from all documents. Also, this process makes it possible to compare and validate whether outcomes are consistent when using only unstructured data and when using both unstructured and structured data. Moreover, the results of this paper are discussed and compared with those of some previous review studies. All in all, the results of this study can provide methodological guidelines for the academic community as well as businesses and government on this topic to enable a comprehensive understanding.

Throughout the study, there are some areas which can be extended as future research. First, the earliest document found and collected under the search strategy and criteria in this paper was published in 2008, and the newest was published in 2017. Therefore, the range of document publication years is only 10 years, limiting the results of TSEA. Therefore, in future research, the search strategy and criteria can be reviewed to include documents from a longer range of publication years to observe a more diverse evolution. Second, apart from document publication years, the number of documents and data are insufficient for more in-depth analysis in this paper. As only freight transportation and warehousing have been included in this paper, more categories of logistics service can be added and included in the search strategy to increase the number of documents. As an extension, with more documents collected, more exhaustive text mining and TOA can be done when examining and contrasting the correlations between concepts, or a lower hierarchy of concepts and terms. Third, currently, the method presented in "Text mining-based analysis method" is applied to IoT in the logistics field in this paper. In future, this method can be applied to IoT in other industries or sectors so that the connections between various sectors in society can be uniformly understood. Yoon et al. [34] suggested that comprehending product opportunities are essential because product development can implement technology opportunities. The text mining-based analysis method used in this paper is limited to identifying IoT technology opportunities. Based on the abovementioned suggestion in Yoon et al. [34], fourth, the future work can extend the method applied in this paper to explore logistics service opportunities and to design new IoT-based logistics services with IoT technology opportunities and logistics service opportunities by integrating tools of new service development (NSD).
Acknowledgements This work is partially supported by the Ministry of Science and Technology, Taiwan, R.O.C. under grant MOST 108-2221-E-009-034-MY3.

\section{Declarations}

Conflict of interest On behalf of all authors, the corresponding author states that there is no conflict of interest.

Open Access This article is licensed under a Creative Commons Attribution 4.0 International License, which permits use, sharing, adaptation, distribution and reproduction in any medium or format, as long as you give appropriate credit to the original author(s) and the source, provide a link to the Creative Commons licence, and indicate if changes were made. The images or other third party material in this article are included in the article's Creative Commons licence, unless indicated otherwise in a credit line to the material. If material is not included in the article's Creative Commons licence and your intended use is not permitted by statutory regulation or exceeds the permitted use, you will need to obtain permission directly from the copyright holder. To view a copy of this licence, visit http://creativecommons.org/licenses/by/4.0/.

\section{References}

1. Aryal A, Liao Y, Nattuthurai P, Li B (2020) The emerging big data analytics and IoT in supply chain management: a systematic review. Surg Endosc Other Interv Tech 25(2):141-156

2. Borgia E (2014) The internet of things vision: key features, applications and open issues. Comput Commun 54:1-31

3. Braun G (2014) The internet of things and the modern supply chain. C3 solutions white paper

4. Cavalcante E, Pereira J, Alves MP, Maia P, Moura R, Batista T, Delicato FC, Pires PF (2016) On the interplay of internet of things and cloud computing: a systematic mapping study. Comput Commun 89-90:17-33

5. Chatterjee S, Goyal D, Prakash A, Sharma J (2021) Exploring healthcare/health-product ecommerce satisfaction: a text mining and machine learning application. J Bus Res 131:815-825

6. Chu C-Y, Park K, Kremer GE (2020) A global supply chain risk management framework: an application of text-mining to identify region-specific supply chain risks. Adv Eng Inform 45:101053

7. Costa A, Guerreiro J, Moro S, Henriques R (2019) Unfolding the characteristics of incentivized online reviews. J Retail Consum Serv 47:272-281

8. Ding Y, Jin M, Li S, Feng D (2020) Smart logistics based on the internet of things technology: an overview. Int J Logist Res Appl. https://doi.org/10.1080/13675567.2020.1757053

9. Golpîra H, Khan SAR, Safaeipour S (2021) A review of logistics internet-of-things: current trends and scope for future research. J Ind Inf Integr 22:100194

10. Hopkins J, Hawking P (2018) Big data analytics and ioT in logistics: a case study. Int J Logist Manag 29(2):575-591

11. IBM (2016) IBM SPSS Modeler Text Analytics 18.0 User's Guide

12. Koot M, Mes MRK, Iacob ME (2021) A systematic literature review of supply chain decision making supported by the internet of things and big data analytics. Comput Ind Eng 154:107076

13. Lee C, Kang B, Shin J (2015) Novelty-focused patent mapping for technology opportunity analysis. Technol Forecast Soc Change 90(Part B):355-365

14. Lee CKM, Lv Y, Ng KKH, Ho W, Choy KL (2018) Design and application of Internet of things-based warehouse management system for smart logistics. Int J Prod Res 56(8):2753-2768 
15. Leskovec J, Rajaraman A, Ullman JD (2020) Mining of massive datasets. Cambridge University Press, Cambridge

16. Ma K, Jiang B (2020) Voice of urban park visitors: exploring destination attributes influencing behavioural intentions through online review mining. Complex Intell Syst. https://doi.org/10. 1007/s40747-020-00223-7

17. Macaulay J, Buckalew L, Chung G (2015) Internet of things in logistics, a collaborative report by DHL and Cisco on implications and use cases for the logistics industry. DHL Customer Solutions \& Innovation, Troisdorf

18. Manyika J, Chui M, Bughin J, Dobbs R, Bisson P, Marrs (2013) A disruptive technologies: advances that will transform life, business, and the global economy. McKinsey Global Institute. http:// www.mckinsey.com/insights/business_technology/disruptive_ technologies

19. Middleton P, Kjeldsen P, Tully J (2013) Forecast: the internet of things, worldwide, 2013. Gartner Research. https://www.gartner. com/en/documents/2625419/forecast-the-internet-of-things-world wide- 2013

20. Moro A, Joanny G, Moretti C (2020) Emerging technologies in the renewable energy sector: a comparison of expert review with a text mining software. Futures 117:102511

21. Nižetić S, Šolić P, de González DLI, Patrono L (2020) Internet of things (IoT): opportunities, issues and challenges towards a smart and sustainable future. J Clean Prod 274:122877

22. Porter AL, Detampel MJ (1995) Technology opportunities analysis. Technol Forecast Soc Chang 49(3):237-255

23. Rejeb A, Simske S, Rejeb K, Treiblmaier H, Zailani S (2020) Internet of things research in supply chain management and logistics: a bibliometric analysis. Internet Things 12:100318

24. Rejeb A, Rejeb K, Zailani S, Treiblmaier H, Hand KJ (2021) Integrating the internet of things in the halal food supply chain: a systematic literature review and research agenda. Internet Things 13:100361

25. Ryu D-H, Lim C, Kim K-J (2020) Development of a service blueprint for the online-to-offline integration in service. J Retail Consum Serv 54:101944
26. Shenkoya T (2020) Social change: a comparative analysis of the impact of the IoT in Japan, Germany and Australia. Internet Things 11:100250

27. Song K, Kim KS, Lee S (2017) Discovering new technology opportunities based on patents: text-mining and F-term analysis. Technovation 60-61:1-14

28. Talavera JM, Tobón LE, Gómez JA, Culman MA, Aranda JM, Parra DT, Quiroz LA, Hoyos A, Garreta LE (2017) Review of IoT applications in agro-industrial and environmental fields. Comput Electron Agric 142(2):283-297

29. Tsai C-W, Lai C-F, Chiang M-C, Yang LT (2014) Data mining for internet of things: a survey. IEEE Commun Surv Tutor 16(1):77-97

30. Wang J, Lim MK, Zhan Y, Wang X (2020) An intelligent logistics service system for enhancing dispatching operations in an IoT environment. Transport Res Part E Logist Transport Rev $135: 101886$

31. Wu J-J, Chang S-T (2020) Exploring customer sentiment regarding online retail services: a topic-based approach. J Retail Consum Serv 55:102145

32. Yoon B, Park Y (2004) A text-mining-based patent network: analytical tool for high-technology trend. J High Technol Manag Res 15(1):37-50

33. Yoon B, Park Y (2005) A systematic approach for identifying technology opportunities: keyword-based morphology analysis. Technol Forecast Soc Chang 72(2):145-160

34. Yoon B, Park I, Coh B-Y (2014) Exploring technological opportunities by linking technology and products: Application of morphology analysis and text mining. Technol Forecast Soc Chang $86: 287-303$

Publisher's Note Springer Nature remains neutral with regard to jurisdictional claims in published maps and institutional affiliations. 